\title{
The Influence of Partial Androgen Deficiency in Aging Men (PADAM) on the Development of Benign Prostatic Hyperplasia and Prostate Cancer
}

\author{
Alexander V. Pechersky \\ Department of Urology, North-Western State Medical University named after I.I. Mechnikov, Russia. \\ a_pechersky@mail.ru
}

\begin{abstract}
Once people reach 40 years of age, they have a decrease in their pool of pluripotent stem cells, and show a violation of tissue renewal, a decrease in the number of cell-producers of testosterone (Leidig cells) and a reduction in testosterone circulating in the blood. Partial androgen deficiency in aging men violates division and differentiation of androgen-dependent cells and increases the risk for development of benign prostatic hyperplasia and prostate cancer. The recovery of testosterone production and regeneration helps make a decrease in proliferative activity, and the rehabilitation of regulation of androgen-dependent cells of the prostate and other tissues and organs, as well as reduce insulin resistance among older men.
\end{abstract}

Keywords: testosterone, partial androgen deficiency in aging men, $5 \alpha$-dihydrotestosterone, $17 \beta$-oestradiol, prostate cancer, androgen blockade, benign prostatic hyperplasia, basic fibroblast growth factor, epidermal growth factor, transforming factor of growth- $\beta$, insulin-similar growth factor-1, insulin, PSA, AR, ER, Ki67, Bcl-2, p53.

\section{INTRODUCTION}

Yury Kerkis named the development of biochemical imbalance to be the main reason for age-related changes in older men in 1940. This imbalance is accompanied by a change in the correlation of the resulting products of physiological processes and reactions [1].

Support of the biochemical balance in the body is determined genetically, and is formed through the process of natural selection. Species with reproductive advantages are most fit for the fight for survival [2], since they provide for the birth and growth of independent life for an adequate number of offspring. At the end of the reproductive period, the parent individuals stop having any influence on the survival of the species; their fate becomes of no value to evolution. At this time the final stage of ontogenesis begins, which is outside the influence of natural selection. It is precisely in this period that we can observe the development of biochemical imbalance (including hormonal imbalance). Although people can keep their social function in their old age, the period of optimal functionality for human, as set by evolution, ends at the age of 35-40 years [3]. Once people reach 35-40 years of age, they have a decrease in their pool of pluripotent stem cells [4], show a violation of tissue renewal, a decrease in the number of cell-producers of testosterone (Leidig cells), and a reduction in testosterone circulating in the blood. This reduction is named partial androgen deficiency of aging men (PADAM) [5].

Cells of a number of tissues, including cells of the glandular epithelium of the prostate gland, have androgen receptors. These cells, in the process of their development from low-differentiated androgen-independent cells, transform into differentiated androgen-dependent cells [6]. Low-differentiated progenitor cells show incipient characters of differentiation and continue division. When dividing, they produce progeny, a part of which continues to divide, while another part remains low-differentiated [7]. When cells acquire androgen receptors, their further division and differentiation becomes impossible without the availability of a sufficient amount of testosterone increted in the physiological impulse regime by Leidig cells [8, 9]. 
The Influence of Partial Androgen Deficiency in Aging Men (PADAM) on the Development of Benign Prostatic Hyperplasia and Prostate Cancer

PADAM violates division and differentiation of androgen-dependent cells. Deficiency of testosterone production results in the development of atrophy of tissues consisting of these cells. [10,11,12]. The answer to insufficient production of testosterone is formed by a series of compensatory-adaptive reactions, affecting autocrine, paracrine and endocrine levels [8]. Compensatory reactions are aimed at additional formation of mitogenic factors (cell growth factors, $5 \alpha$-dihydrotestosterone, $17 \beta$-estradiol, insulin, somatotropic hormone and other factors), having a stimulating effect on proliferation of the epithelium. A decrease in the level of testosterone induces an increase in mitotic activity, disruption of regulation of cells, as well as inhibition of apoptosis [8]. The intensity of these reactions is proportional to the degree of reduction in testosterone production $[8,13]$. In view of the interdependence of the neurohumoral regulatory processes [14], a reduction in the production of testosterone is reflected on endocrinal regulation as a whole $[10,13]$. PADAM provokes a breach of the mechanisms of regulation in the system of the gonads-hypophysis-hypothalamus, including of an increase in the activity of the hypophysis [15].

The type of sexual constitution is determined by an individual adjustment of the endocrine system and the corresponding receptor expression of receptors regulated by its tissues. In case of a strong type of male sexual constitution, the body uses the full potential of testosterone incretion by Leidig cells. A necessary condition for normal development of their androgen-dependent tissues is an increased concentration of testosterone in blood. In the absence of reserve capacities of an organism for additional formation of testosterone in men with a strong sexual constitution type, even a small reduction in testosterone formation after 40 years causes disorder of androgen-dependent cell development. Developing the accompanying compensatory reactions (aimed at stimulation of mitotic activity) and atrophy of androgen-dependent tissues result in a significant increase in the risk of prostate cancer development in men with strong sexual constitution, and cause early baldness [8, $10,11,12]$.

An increase in mitogenic stimulation in patients older than 40 years old, associated with a decrease in sex hormones, is complemented by an increase in mitogenic stimulation caused by violation of tissue regeneration $[8,10,11,12,13,16,17]$. The epithelium of all tissues is located on the basal membrane, which is part of the extracellular matrix. Renewal of old epithelial cells takes place through the division of poorly differentiated progenitor cells of the epithelial layer and replacing them. Progenitor cells are replenished by committed stem cells (tissue-specific stem cells) that migrate through the extracellular matrix and basal membrane [7, $11,12,16,17]$. The reduced pool of pluripotent stem cells in people after 35 years old leads to disorder in tissue-specific stem cells replenishment of poorly differentiated progenitor cells, which replace dead old cells. After age 35, humans develop insufficient arrival of migratory committed stem cells (tissue-specific stem cells) to the epithelial layer, which is compensated for by excessive stimulation of division of poorly differentiated (progenitor) epithelial cells by cell growth factors (formed paracrinally and autocrinally). Continuous excessive stimulation of mitogenic activity of epithelial cells leads to their malignant transformation - to cancer. Similarly insufficient arrival of committed stem cells (tissue-specific stem cells) for replenishment of progenitory cells in other tissues can lead to development of malignant process [11, 12, 16, 17].

In particular, on the background of a reduction in the pool of stem cells in men over 35 years old, there is a reduction in the number of poorly differentiated progenitor cells of the epithelial layer of the prostate gland, which become unable to adequately replace dead old differentiated cells (Principal cells). In response to the reduction in the pool of stem cells and subsequent reduction in the number of poorly differentiated progenitor cells as a compensation by the autocrine-paracrine mechanism production of cellular growth factors (insulinlike growth factor-1, epidermal growth factor, basic fibroblast growth factor, etc.), aimed at stimulation of poorly differentiated progenitor cells for replacement of old dead cells, is increased. Increased production of cell growth factors due to a reduction in the pool of stem cells and depletion of poorly differentiated progenitor cells does not lead to generation of an adequate amount of progenitor cells that provide replacement of dead 
The Influence of Partial Androgen Deficiency in Aging Men (PADAM) on the Development of Benign Prostatic Hyperplasia and Prostate Cancer

old cells. With age, the number of poorly differentiated progenitor cells gradually decreases. Naturally, with age, increment mitogenic stimulation increases and becomes constantly high [11,12,16,17]. Basic fibroblast growth factor (bFGF), epidermal growth factor (EGF), insulin-like growth factors I and II (IGF-I, IGF-II) and also some other cellular growth factors possess the expressed mitotic activity, and are pro-motor factors of carcinogenesis [18]. The constant increased levels of cellular growth factors stimulating proliferation of poorly differentiated progenitor epithelial cells and progenitor cells of other tissues lead to metaplasia, and subsequently to malignization $[11,12,17]$. These factors significantly increase the risk of development of prostate cancer and cancer of other organs. Stimulation of proliferation with these factors of paraurethral glands leads to the development of benign prostatic hyperplasia $[6,8,18,19,20]$. The probability of development of prostate cancer and benign prostatic hyperplasia increases significantly after forty years of age $[8,19,20,21]$. At this age, men show a reduction of testosterone circulating in the blood [5].

\section{The Effect of Testosterone Concentration on the Intensity of $5 \alpha$-Dihydrotestosterone and $17 \beta$ - Oestradiol Formation}

The formation of $5 \alpha$-dihydrotestosterone and $17 \beta$-oestradiol increases in men older than 40-50 years. A minimum accumulation of $5 \alpha$-dihydrotestosterone and $17 \beta$-oestradiol is noted in experimental mediums with a normal physiological level of testosterone in the blood plasma of men. Any replacement of the content of testosterone in the medium (either an increase or decrease) leads to a consistent growth in the formation of $5 \alpha$-dihydrotestosterone and $17 \beta$-oestradiol, and, consequently, to an increase in aromatase activity and $5 \alpha$-reductase. Thus, when the concentration of testosterone was reduced to $3 \mathrm{ng} / \mathrm{ml}(10.41 \mathrm{nmol} / \mathrm{l})$, the level of $5 \alpha$-dihydrotestosterone rose by 1.82 times. When the level of testosterone was reduced to $1 \mathrm{ng} / \mathrm{ml}(3.5$ $\mathrm{nmol} / \mathrm{l}$ ) the level of $5 \alpha$-dihydrotestosterone rose by 3.3 times. Where larger concentrations of testosterone were found, growth in the content of $5 \alpha$-dihydrotestosterone was also noted: in a concentration of $12 \mathrm{ng} / \mathrm{mL}$ ( $41.6 \mathrm{nmol} / \mathrm{l})$, there was growth by 2.9 times; in a concentration of $24 \mathrm{ng} / \mathrm{ml}(83.3 \mathrm{nmol} / \mathrm{l})$ - by 4.9 times; and in a concentration of $600 \mathrm{ng} / \mathrm{ml}(2082.0 \mathrm{nmol} / \mathrm{l})$ - to growth by 10.5 times. Similar results are found in the dynamics of the accumulation of $17 \beta$-oestradiol in the incubational experimental medium [22].

The increase in the activity of $5 \alpha$-reductase and aromatase is determined by the physiological role of testosterone, estrogens, and $5 \alpha$-dihydrotestosterone. Testosterone takes part in processes of division and differentiation of cells with androgen receptors. A reduction in the formation of testosterone inhibits the development of cells with androgen receptors in a whole series of tissues based on measures of ageing [8, 22]. Testosterone and $5 \alpha$-dihydrotestosterone connect to one and the same receptor. The ability to connect with the androgen receptor is higher for $5 \alpha$-dihydrotestosterone in comparison with testosterone [14]. Therefore, when the level of testosterone goes down, there is a corresponding compensatory response in the increase of the level of $5 \alpha$-dihydrotestosterone in men with PADAM [13]. On the contrary, a low $5 \alpha$-dihydrotestosterone level is a promoting factor in the progression of prostate cancer and decreased survival in prostate cancer patients [23].

An increase in the activity of aromatase and $5 \alpha$-reductase is directed at compensating for the lack of mitotic activity of testosterone $[8,13]$. Estrogens induce intensive karyokinesis in tissues containing specific receptors [18]. Both $5 \alpha$-dihydrotestosterone and testosterone, connecting with one and the same intracellular receptor [14], stimulate proliferation activity of cells [24]. The stimulating effect of $5 \alpha$-dihydrotestosterone is strongest during the synergic influence of estrogens $[8,10]$.

$5 \alpha$-dihydrotestosterone does not serve as a complete replacement of testosterone: unlike testosterone, it is formed in tonic regime, while production of $5 \alpha$-dihydrotestosterone does not correspond to the impulsive formation of LH. Moreover, the greater decrease in testosterone production as men get older limits the formation of $5 \alpha$-dihydrotestosterone and the manifestation of the given compensatory mechanism, even though there is an increase in $5 \alpha$-reductase activity $[8,13,22]$. Conversely, rehabilitating the level of testosterone to its physiological 
The Influence of Partial Androgen Deficiency in Aging Men (PADAM) on the Development of Benign Prostatic Hyperplasia and Prostate Cancer

level by testosterone replacement therapy leads to a decrease in the production of $5 \alpha$-dihydrotestosterone and $17 \beta$-oestradiol, and leads to prevention of benign prostatic hyperplasia and prostate cancer $[8,13,19]$.

When the level of testosterone goes up, the increase in the activity of aromatase and $5 \alpha$-reductase, apparently, also has a compensatory character, since the main way to reduce the level of testosterone is to increase the intensity of testosterone's metabolism [25]. In this case, some of the interim products include $5 \alpha$-dihydrotestosterone and $17 \beta$-oestradiol $[8,22]$, which become the reason for the development of prostate cancer in animals which got large doses of androgens in experiments $[6,26]$.

\section{The Influence of Changes in the Testosterone Level on the Levels of Hormones and Cell Growth} Factors in Men

A decrease in the level of testosterone for a rather short time interval allows makes it possible to connect the occurring changes only with the given factor. Accordingly, (in patients with prostate cancer), it is possible to consider the pathological processes accompanying orchiectomy / androgen blockade to be similar to what develops during a decrease in formation of testosterone in men 35-40 years old.

After the orchiectomy, an increase in the level of STH was observed [8], which depends on the stimulation of somatoliberin [14]. An increase in the incretion of somatoliberin and repression of the incretion of somatostatin is observed during reduction of the sensitivity of the hypothalamic centers to inhibition of glucose. The given changes are found after 35-40 years of age. Insulin resistance promotes an increase of STH. After orchiectomy, the level of insulin regularly increased [8]. Formation of STH is additionally stimulated by Vitamin D [14], the level of which increased after orchiectomy [8].

The decrease in the levels of testosterone and $17 \beta$-estradiol was accompanied by an increase in aromatase activity. This confirms the increase of the level of estrone. Just like $17 \beta$-estradiol, estrone is formed under the influence of aromatase [14]. The formation of estrone from adrenal androgen - androstendion, allows one to evaluate the activity of aromatase even when the level of testosterone is significantly reduced after orchiectomy [8]. Seeing that when the level of testosterone is decreased the activity of aromatase as well as of $5 \alpha$-reductase increases [13], the increase in aromatase activity after orchiectomy points to growth of $5 \alpha$-reductase activity. Thus, the reason for the decrease in production of $5 \alpha$-dihydrotestosterone and $17 \beta$-estradiol in patients following orchiectomy is that the level of testosterone decreases significantly (from which $5 \alpha$-dihydrotestosterone and $17 \beta$-estradiol form). Despite this, the enzymatic activity of aromatase and $5 \alpha$-reductase, contrarily, increases [8].

The reduction of the levels, and, accordingly, of the kariokynetic activity of testosterone, $5 \alpha$-dihydrotestosterone (and, accordingly, of EFR [24]), and 17 $\beta$-estradiol after orchiectomy is compensated for not only by an increase in aromatase and $5 \alpha$-reductase activity, but also by an additional exertion of production by cells of peptide growth factors. The given changes are conditional upon the endocrinal activators of cell reproduction [8]. In all patients after orchiectomy, there ensued a reliable increase in the level of bFGF [8]. bFGF has the most pronounced stimulating influence upon the proliferation of the epithelia. In terms of its kariokynetic activity, bFGF surpasses several other growth factors [6].

After orchiectomy, an increase in the formation of IGF-1 was observed [8]. This was promoted by an increase in the incretion of STH. STH and IGF-1 manifest pronounced karyokinesis [14]. The receptor of IGF-1 is similar to the receptor of insulin, and therefore IGF-1 can connect with the receptors of insulin and activate them [14]. The increase in the levels of IGF-1 and insulin in patients after orchiectomy is a compensatory answer to the development of insulin-resistance. Insulin, along with IGF-1, raises the kariokynetic activity of cells. From these positions, it's possible to examine insulin-resistance as an instrument for an increase in the levels of insulin, STH, IGF-1 and, accordingly, their kariokynetic activity [8]. The increase in the levels of the given indicators is characteristic of the stage of the promotion of tumor growth [18]. 
The Influence of Partial Androgen Deficiency in Aging Men (PADAM) on the Development of Benign Prostatic Hyperplasia and Prostate Cancer

The increase in aromatase activity and the levels of the majority of growth factors after orchiectomy indicates that compensatory-adaptation reactions, which develop when the level of testosterone goes down, are directed towards an increase in the mitotic activity of the cells. Their expression is proportional to the degree of reduction of the testosterone level [8].

The given changes combine with the oppression of the formation of $\beta$ TGF [8] - a factor responsible for the consequential passage by the cell stages of the stages of differentiation and the start of apoptosis [18].

Thus, the reduction of the level of testosterone causes an increase in kariokynetic activity, a breach in regulation of cell-differentiation, and the start of apoptosis. The given changes create the conditions for the development of a new tumor from low-differentiated androgen-independent epithelial cells, despite the dystrophic changes happening in the androgen-dependent cancer cells of the primary tumor [8]. For this reason, antiandrogen therapy in addition to atrophy of tumor tissue leads to an increase in Gleason grading of the remaining tumor cells. Long-term antiandrogen therapy reduces the size of nuclei, and polymorphism of androgen-dependent cells nuclei decreases. The use of inhibitors of $5 \alpha$-reductase has a similar, but less pronounced effect [27]. Morphological findings are supported by clinical data. The use of finasteride increases the risk of prostate cancer development with a high grade Gleason score [28]. The low level of $5 \alpha$-dihydrotestosterone is associated with prostate cancer progression, and a decrease in survival of patients with prostate cancer [23].

\section{The Role of Testosterone in Regulation of the Expression of Genes of Several Proliferation Factors}

Due to the inter-dependence of the neurohumoral regulatory processes [14], inadequate testosterone production as a result of a reduction in the number of cell-producers of testosterone (Leidig cells) has an influence on the entire endocrinal regulation system as well. An entire series of genetically determined compensatory-adaptive reactions takes place. These changes are combined with an increase or a decrease in the expression of the according genes. In addition to regulation of physiological processes in the genome as an evolutional generated biological program, there are fixed compensatory responses to various pathological conditions. The male organism has formed standard genetically-determined variants of functioning of the endocrinal and paracrinalautocrinal regulation systems over the course of evolution. These variations match both normal conditions and the majority of pathological states a man can have, one of which is a reduction in the production of testosterone. The changes represent a series of compensatory-adaptive reactions which develop among men with PADAM, and have a systematic character [29]. A decrease in the formation of testosterone with age and the occurrence of infringement of division of androgen-dependent cells of many tissues of an organism in the superfluous formation on endocrinal, paracrinal, and autocrinal levels of all possible factors which can be involved for stimulation of cell division, is genetically determined [29].

The absence of adequate incretion of testosterone by Leidig cells in response to LH activity is accompanied by an expression in bFGF, EGF, and bcl-2 genes, as well as by a decrease in the expression of the insulin receptors gene. When partial age-related androgen deficiency is corrected, however, the expression of these genes is reversed. This suggests that the changes in gene expression which take place due to PADAM are not permanent [29]. The change in the pattern of gene expression which takes place during the process of phylogenesis depends on the level to which testosterone production has deviated from physiological norms. The new variations of the functioning of the endocrinal and paracrinal-autocrinal regulation systems for testosterone production are made through a mechanism of negative feedback [29].

The series of compensatory reactions which forms is aimed at making up for the inadequacy of the mytogenic action of testosterone through the means of an increase in aromatase and $5 \alpha$-reductase activity, and increased synthesis of a series of cell growth factors, as well as higher levels of endocrinal activators of mitosis (somatrope hormone, insulin) and vitamin D [8]. The expression of AR and ER is added to by increased $5 \alpha$-reductase and 
The Influence of Partial Androgen Deficiency in Aging Men (PADAM) on the Development of Benign Prostatic Hyperplasia and Prostate Cancer

aromatase activity [22]. An increase in the level of mitotic factors in the blood plasma puts both androgendependent and androgen-independent cells of the organism under equal conditions. The result of PADAM is increased expression of genes of several cell proliferation factors and a decrease in the expression of the gene of insulin receptors in older-aged men. An increase in proliferative activity, together with insulin resistance, is a partial result of the expression of metabolic syndrome [8, 29].

A decrease in the quantity of insulin receptors (insulin resistance) leads to a reactionary increase in the level of insulin. At this point, insulin-independent sugar diabetes (type 2 diabetes) starts to develop. Insulin increases mitotic activity [14]. From this point of view, insulin resistance can be seen as a mechanism for increasing the level of insulin, and correspondingly, for increasing its mytogenic activity [29]. An increased level of insulin is characteristic of the stage of tumorous growth promotion [18].

The inverse development of the given pathological processes can be received through androgen replacement therapy. The necessary level of testosterone is formed in the body as a response to LH incretion when androgen-replacement therapy in patients with PADAM is done properly. Autocrine-paracrine interaction is also normalized thanks to the obstruction-free passage of androgen-dependent cells through the testosteronedependent cell development stage. When testosterone regulation is rehabilitated, there is no longer any need for compensatory-adaptive reactions to take place in the body, as happens in men with PADAM. One can observe a decrease in the expression of the ER, bFGF, EGF, and bcl-2 genes, and an increase in the expression of the IR gene [29].

The given changes in the level of expression of these genes is accompanied by a decrease in the levels of estrogen, bFGF and insulin in the blood plasma in men with PADAM who were given androgen-replacement therapy $[19,29]$.

Extragonadal Production of Testosterone and Changes in the Expression of Receptors of Steroid Hormones in the Development of Partial Androgen Deficiency in Aging Men (PADAM)

Disruptions in the process of differentiation of androgen-dependent cells, caused by PADAM, are morphologically created by atrophy of the tissues consisting of these cells. In particular, atrophy of the epithelium of acenuses of the prostate is observed. Violation in the development of cells at the testosterone-dependent stage of differentiation in the presence of PADAM precedes malignant growth. Background alterations of malignant tumor development can be observed in tissues surrounding a tumor (tissues of the peritumorous zone) [10].

In order for there to be replacement of the shortage of mitotic activity of testosterone, a whole series of compensatory-adaptational reactions forms [8]. The given compensatory changes are expressed through intensification in production of factors increasing cell division, as well as by an increase of stimulation of the formation of testosterone $[8,10]$.

Each of the eukaryotic cells (with minor exceptions) is a carrier of the individual's entire genetic information. While the genome is almost identical for all cells in the organism, their proteome and metabolome are determined by inner and outer physiological factors. The fact that cells are included in compensatory reactions means that this process is capable of modulating their metabolome, which is proven by the hormonal activity of a significant number of non-endocrinic cells in the organism. Extragonadal production of testosterone [10], as well as the synthesis of the analogues of hypophysic hormones by cells of the cancerous tumor of the prostate gland [30], extragonadal production of estrogens by fatty tissue and several other types of tissue among women [31] in the menopausal period, and synthesis of renin by myocytes of the wall of the afferent arteriole, transformed into epitheliod cells, and by mesangiocytes of the kidney during expressed, long-term ischemia of kidney tissues [32] and other examples, show that potentially, any cell of the organism is able to produce hormones. Hormonal activity of tissues (which aren't endocrinal or neuroendocrinal by nature) is conditional upon either insufficiency of the corresponding endocrinal factor (for example, extragonadal production of 
The Influence of Partial Androgen Deficiency in Aging Men (PADAM) on the Development of Benign Prostatic Hyperplasia and Prostate Cancer

androgens among men with PADAM and of estrogens during the menopausal period) or upon the assistance of the developing hormone in the chain of the compensatory-adaptational reactions [10] (for example synthesis of prolactin by the tissue of cancerous tumors of the prostate gland [30], which leads to an increase in aromatase activity [18]). Apparently, the situational manifestation of compensatory hormonal activity by the majority of cells and tissues (including tumorous cells) forms a diffusive endocrinal system (APUD-system) [10, 33].

Among the majority of patients with PADAM, the indices of the level of testosterone were within the normal referential interval, which can be explained by the extragonadal production of testosterone. Extragonadal testosterone production is directed at compensation of partial age-related androgen deficiency. The compensatory incretion of hormones by cells and tissues for which endocrinal functions are not typical (including tissues of the tumors) is not regulated [14, 32, 34], and is inadequate. Atrophy of the epithelium in the glands and the increased expression of AR in these tissues of the peritumorous zone among patients with prostate cancer, as compared to the analogous index in the prostate of young men, point to the inadequacy of the compensatory mechanism created by extragonadal synthesis of testosterone during PADAM. Thus despite additional extragonadal testosterone production, there is no inverse development of compensatory reactions, as conditioned by PADAM, including an increase in proliferate activity [10].

The strongest expression of extragonadal testosterone production among men with andropause is observed when there is a significant increase in mytotic activity of cells when they go through malignant transformation. The malignant transformation of cells is the most strongly expressed form of the manifestation of compensatory changes as PADAM develops [10], which determines its physiological role.

Insulin, basic fibroblast growth factor (bFGF), and epidermal growth factor (EGF) stimulate extragonadal production of testosterone by other tissues, for which such a function isn't common under normal conditions. Thus, among the majority of patients studied, even despite the fact that these patients with PADAM, when making a primary analysis normal levels of common testosterone were found [10,33].

The malignant transformation of a whole set of tissues is accompanied by the manifestation of hormonal activity in these tissues [14]. An increase in the level of testosterone is achieved not only by hypophysial stimulation of Leidig cells, but by the use of synthesis of testosterone by other tissues as well, for which, in normal conditions, such a function is not typical. The given conclusion is confirmed by the significant prevalence of the amount of testosterone in the peritumorous tissues of the prostate, or in the tumorous tissue among patients with cancer of the prostate, bladder, or rectum as compared to the level of testosterone in the blood serum of these patients. Among patients with prostate cancer, the levels of testosterone in the malignant tissue were routinely higher than the analogous indices in the tissues of the peritumorous zone [10].

This shows that partial androgen deficiency of aging men is compensated for by production of testosterone outside the gonads. The predominance of the level of testosterone in the tumorous tissue as compared to the peritumorous zone attests to the intensification of testosterone production outside the gonads together with the malignant transformation of cells producing testosterone. The largest expression of the given compensatoryadaptational reaction occurs when the level of mitotic activity of the cells is significantly increased during their malignant transformation [10].

The developing compensatory-adaptative reactions during a decrease in the level of testosterone are most of all directed towards an increase in the mytotic activity of the cells. Their expression is proportional to the level of the decrease in the level of testosterone. In particular, an increase of $5 \alpha$-reductase and aromatase activity, which synthesizes $5 \alpha$-dihydrotestosterone and estrogen, is observed in patients whose testosterone levels decrease $[8,13,33]$. 
The Influence of Partial Androgen Deficiency in Aging Men (PADAM) on the Development of Benign Prostatic Hyperplasia and Prostate Cancer

The receptor apparatus which accepts the signal, together with cells, tissues and organs that make incretions, form a unified interdependent system [14]. Activation of receptors on the cell membrane increases the effect of the according regulating factor [34]. The expression of AR and ER is added to by increased $5 \alpha$-reductase and aromatase activity. This increase is observed when the testosterone level goes down. The expression of AR and ER in the tissues of the peritumorous zone of the prostate and the expression of ER in the tissues of the peritumorous zone of the rectum, supplement the increase in the activity of aromatase and $5 \alpha$-reductase, which are observed when the level of testosterone drops [10].

The intensification of steroidogenesis in the tumorous tissue can be caused by the presence in this tissue of lymphocyte-macrophage infiltrate. Lymphocytes and macrophages are capable of synthesizing testosterone. Lymphocytes and macrophages also have aromatase activity, transforming androgens into estrogens [31]. Lymphocyte and macrophage infiltrate of tumors of the prostate gland, bladder, and rectum, as well as in the peritumorous zone of the given organs, locally supplement the overall compensatory reaction directed towards raising mitotic activity. The presence of lymphocytes and macrophages in the process of steroidogenesis affirms the conception of immunal and neuroendocrinal unity [10].

Extragonadal synthesis of steroidal hormones is stimulated by hormonal and autocrino-paracrinal factors. Prolactin, insulin, vitamin D, insulin growth factor-1 (IGF-1), basic fibroblast growth factor (bFGF) and epidermal growth factor (EGF) have a strong influence on this process $[18,31]$. The increase in the level of the given factors is characteristic for development of metabolic syndrome (X-syndrome), and is seen when the level of testosterone decreases $[8,19]$. A rise in the levels of STH, insulin, estradiol, $5 \alpha$-dihydrotestosterone, vitamin D, bFGF, IGF-1 and EGF among men with PADAM $[8,13]$ stimulate cell proliferation (increase expression of Ki67) and inhibition of apoptosis (increased expression of bcl-2), found in the peritumorous zone among observed patients to a considerable extent. In this way, atrophical changes in androgen-dependent cells, stipulated by PADAM, are accompanied by an increase in the risk of blastomatous transformation [10]. An increase in the given factors in the blood plasma involves androgen-independent tissues in the formation of compensatory reactions as a response to the development of PADAM. Thus, among the patients observed, extragonadal production of testosterone by tumorous tissue of the rectum and bladder was revealed. Immunohistochemical study of the tissues of these organs among the young men, as well as in the peritumorous zone among patients with bladder or rectal cancer, did not reveal the presence of AR. In the peritumorous zone of the given patients Ki67 and bcl-2 were expressed regularly [10].

The increased expression of p53 (which determines normalization of cell growth and stops proliferation of tumurous cells), which was shown in the peritunorous zone in patients with cancer of the prostate, bladder, or rectum, helps to control the increased proliferative activity, which develops as an answer to the inadequacy of the mytotic action of testosterone during PADAM $[8,10]$. The increase expression of p53 adds to the increase during PADAM of the levels of transforming factor of growth- $\beta$ (TGF $\beta$ ) and cytotoxic factors of anti-cancerous cell immunity [8]. During a long and significant increase of mitotic stimulation, their effectiveness becomes inadequate, which was seen when tumorous tissue developed among the patients observed in this study [10].

Extragonadal production of testosterone by a whole series of tumors and tissues of the peritumorous zone, accompanied by an increase in proliferative activity, is predetermined to a significant extent by partial androgen deficiency of aging men (PADAM). The given changes are directed at compensation of testicular deficiency (in particular at overcoming the androgen-dependent stage of the development of androgen-sensitive cells), and are the partial manifestation of metabolic syndrome (X-syndrome). The atypical cells, which unavoidably develop under metabolic syndrome, are dealt with by means of the immune process, the capabilities of which become less and less adequate in the given circumstances [10]. 
The Influence of Partial Androgen Deficiency in Aging Men (PADAM) on the Development of Benign Prostatic Hyperplasia and Prostate Cancer

The pathological processes described in this study concern all organs and tissues of the organism, including both androgen-dependent, and androgen-independent tissues, thereby raising the risk of their tumorous transformation [10].

The Influence of Partial Androgen Deficiency Among Aging Men on the Impulse Mode of the Incretion of Some Hormones and Mitotic Activity

Information from the central nervous system, which is transferred in the form of nerve impulses which follow one after another at regular intervals, is transformed into an impulse rhythm of formation of hormones $[9,33]$.

As testosterone production goes down as men get older, the agreement between the central and peripheral core of the hypothalamus-hypophysis-gonad system is broken down. Leidig cells are not able to ensure adequate production of testosterone in response to the incretion of LH among men after 35-40 years of age. The patients who have PADAM demonstrate that the impulse incretion of gonadotropin-releasing hormone and LH isn't accompanied by an adequate impulse incretion of testosterone. The central nervous system understands this state to be an even deeper manifestation of androgen deficit [9]. There is thus a compensatory increase in the levels of gonadotropin-releasing hormone, LH, and FSH, using a mechanism of inverse feedback [14]. Despite the increase in the level of testosterone, the mode for testosterone incretion remains non-physiological, and gradually becomes tonic. The reaction of Leidig cells in tonic mode to the impulse formation of gonadotropinreleasing hormone and LH among men with PADAM is accompanied by a gradual transition to a tonic regime of hormone incretion by the hypophysis and hypothalamus [9].

These changes lead to limitation and distortion of the information being transferred, which regulates a whole series of physiological processes including proliferate activity. Suppression of the impulse incretion of gonadotropin-releasing hormone, in turn, is reflected in the correlation of LH and FSH, and in the formation of cell growth factors [9]. Thus, LH is the stimulator of synthesis of IGF-1 in Sertoli cells. IGF-1 strengthens the expression of LH receptors on Leidig cells, and thereby activates steroidogenesis. FSH has a slowing-down influence on the creation of transformation growth factors in Sertoli cells. Transformation growth factors reject steroidogenesis in Leidig cells [14]. In relation to this, the frequency of the rhythm of formation of gonadotropinreleasing hormone, which determines the correlation between LH and FSH, has a direct influence on the level of cell growth factors, and, accordingly, on cell proliferation [9].

The long and continuous (in the tonic mode) influence of gonadotropin-releasing hormone leads to desythesization of this hormone's receptors on gonadotropin cells, and to suppression of the incretion of LH and FSH, despite the remaining deficit of testosterone [14]. Thus, among the patients with PADAM, the original levels of LH and FSH don't exceed the normal referential interval [9]. The use of analogues of gonadotropinreleasing hormone, which have a suppressing influence on gonadotropin cells of the hypophysis as well as on Leidig cells [14], is based on this effect [9].

An increased level of prolactin, which is observed among patients with PADAM [8], leads to suppression of the impulse incretion of gonadotropin-releasing hormone and, consequentially, of the impulse rhythm of production of LH, FSH, and testosterone, as well as to suppression in impulse incretion of STH [14].

Insulin resistance, which goes along with PADAM [8], leads to the exhaustion of $\beta$ cells [14] and to a breakdown in the impulse incretion of insulin [9].

The signal which regulates mitotic activity is sent through G-protein, which ensures that the hormonal signal is sent a number of times. G-protein in its activated form stimulates the synthesis of cyclical adenosine monophosphate from adenosine triphosphate through adenylate cyclase, and stimulates the synthesis of cyclical guanosine monophosphate from guanosine triphosphate through guanylate cyclase. This leads to the launch of the cascade mechanism for activating inner-cell proteins. Phosphorylation is the most important post- 
The Influence of Partial Androgen Deficiency in Aging Men (PADAM) on the Development of Benign Prostatic Hyperplasia and Prostate Cancer

translation modification of protein molecules. Phosphorylation activates or inhibits the fermentive activity of protein molecules. Dephosphorylation leads to inactivation of the ferment, and to a return to the original state by stopping the transfer of the mitotic signal. Hormonal regulation of mitotic activity of normocytes is discreet and impulsive. The change from the impulse formation of hormones to a tonic incretion regime inhibits the onset of the physiologically necessary dephosphorylation phase. The signal chain, which carries the mitogenic signal, takes on a continually active state. The cell is thereby held in a regime of constant mitotic activity. The activity of adenylate cyclase and guanylate cyclase gets an additional stimulus from ions of $\mathrm{Ca}^{++}$and products of peroxide oxidation of lipids $[9,33,35,36]$. The levels of the latter go up among patients with age-related deficiency of testosterone production [8].

An age-related decrease in the production of peripheral hormones (including PADAM) leads to a loss of impulse rhythm and the establishment of a tonic incretion mode for luteinizing (LH), follicle-stimulating (FSH), and somatotropin (STH) hormones, as well as cortisol and insulin among men with PADAM, as well as to an increase in mitotic activity [9].

\section{Reaction of the Immune System to Incise Mitotic Activity}

The dependency of cell immunity on PADAM is affirmed by the expressions of AR, ER, PR, bcl-2 and p53 of lymphocytes and macrophages of infiltrate of the tumor and peritumorous tissues among the patients studied [10].

The action of cell immunity is carried out through formation of cytotoxic factors (TNF $\alpha$ and others), secreted by activated macrophages, monocytes by the cells $[37,38]$. Cytolysis of the cells-targets of the malignant tumor leads to its incomplete necrosis [37]. The given process has an autoimmune nature. The cytolitic action of the T-cells on the freshly-formed tumorous cells is shielded by receptors which are limited by killing (KIR) [37], and therefore necrosis develops in the most early-formed divisions of the tumor.

Acid phosphatase, which posseses cytolitic activity, is held in macrophages, in primary (auzorophile) granules of neutrophiles and in several other cells of the immune system [37, 38]. Alkaline phosphatase also posseses cytolitic activity. It is held in secondary (specific) granules of neutrophiles and, equally to other highly-active substances and enzymes, is capable of causing death in tumorous cells [37]. PSA is a serine proteinase - an enzyme, relating to the class of hydrolases. $\alpha 1$-antichemotripsine and $\alpha_{2}$-macroglobulin connect with PSA, converting it into an inactive form [18]. Besides the epithelia of the prostate gland, the serine proteinases are formed by a whole set of cells. After orchiectomy a reliable decrease of the initially-increased level of TNF $\alpha$ was determined. The given changes were accompanied by a set of cytotoxic factors of cell immunity [8].

Granules of macrophages, neutrophiles, and cytotoxic T-cells also contain serine proteinases and esterases of the chemotripsin type. The regulation of the activity of the proteinases is done by their inhibitors, secreted by the macrophages: by $\alpha$-antichemotripsin and $\alpha_{2}$-macroglubin. Besides the manifestation of cytotoxicity, serine proteinases can cause fragmentation of DNA in the cells-targets and the start of the program of apoptosis, acting on the path of inner-cell signalization. Serine proteinases participate in the antibody-independent alternative path of activation of the compliment $[37,38]$. Thus the increase of PSA, determined before orchiectomy in patients with prostate cancer, is not only the consequence of a incretion of the malignant cells of the epithelia of acinuses germinating the surrounding tissues entering into the bloodstream, but also the expression of an overall compensatory activation of the system of the complement and of cell immunity [8].

The increased values of acid phosphotase, alkaline phosphotase, PSA, and TNF $\alpha$ determined before orchiectomy and after orchiectomy testifies to the development of a compensatory reaction of anti-tumor cell immunity in response to the increase of proliferate activity among patients with PADAM. The given reaction is directed at the utilisation of the formation of atypical cells and the regulation of apoptosis. The reduction of regulatory as 
The Influence of Partial Androgen Deficiency in Aging Men (PADAM) on the Development of Benign Prostatic Hyperplasia and Prostate Cancer

well as of the majority of cytotoxic factors of cell immunity testifies to the decompensation of mechanisms of anti-tumor immunity in patients after orchiectomy [8].

The androgen dependency of the reaction of cell immunity is confirmed by the presence of AR in lymphocytes and macrophages [10]. The significant reduction of the level of testosterone (after orchiectomy) causes the decomposition of antitumor immunity [8].

The influence PADAM on the Increased Tone of the Smooth Muscle and Development of Lower Urinary Tract Symptoms (LUTS)

Changes in hormonal regulation are reflected on the path of the transmission of the signal. cAMP is an intracellular mediator. Initiation of the cAMP-path of signal transmission develops after binding together of the receptor of the cell surface with the according ligand [7]. A number of peptide hormones (luteinizing hormone, follicle-stimulating hormone, parathyroid hormone, adrenocorticotropic hormone, and several others) can serve as a ligand [14]. Thus, an increase in the production of luteinizing hormone, follicle-stimulating hormone, parathyroid hormone, adrenocorticotropic hormone and several other peptide hormones, under partial agerelated androgen deficiency $[13,19]$, leading to activation of cAMP-paths of signal transmission, besides other effects, influence the regulation of the tone of smooth muscle fiber [39].

In order to understand pathogenetic mechanisms for increasing tone of smooth muscle fiber together with cAMP-paths of signal transmission, it's necessary to keep in mind the inositol phospholipid path (Ca-messenger system) from surface cell receptors. The mitotic effect of the majority of cell growth factors takes place through the inositol phospholipid path of signal transmission [7], as well as through the cAMP-paths of signal transmission (including activity of tyrosine-kinase) [39].

The effect of a series of cell growth factors (when involving the Ca-messenger system) is mediated by the formation of diacilglicerol. Diacilglicerol activates protein kinase $\mathrm{C}$, which is accompanied by stimulation of proliferation of cells. Liberation of $\mathrm{Ca}^{++}$from cell repositories promotes the given process, leading to increased tone of smooth muscle cells. Diacilglicerol then breaks down to arachidonic acid, which is necessary for synthesis of prostaglandin. Initiation of the synthesis of prostaglandin leads to an additional clonus of smooth muscle cells [7]. These mechanisms, apparently, not only promote a violation of microcirculation, but also the development of LUTS (as a result of the increase in tone of smooth muscles of the urinary bladder and the prostate gland) and other pathological states among aging men as a result of increased smooth muscle tone [39].

Affecting the path of signal transmission shouldn't be viewed as the only way to solving the problem of increased tone of smooth musculature among people over 35-40 years old. The studied mechanisms of signal transmission are universal: they are used in all cells of animals and man. Therefore, pharmacological medications which have an influence on the signal transmission path don't have a selective medical effect. The use of such medications (especially over a long period of time) is limited by a series of side effects [39].

The effectiveness of androgen-replacement therapy for reducing LUTS among patients with benign prostate hyperplasia and PADAM is proven by clinical studies [13]. A decrease in LUTS when conducting androgenreplacement therapy is also caused by recovery of the structure of atrophic androgen-dependent tissues of the prostate and the neck of the urinary bladder. An age-related decrease in production of sex hormones, leading to atrophy of tissues that depend on them, apparently leads to a decrease in the threshold of affectability of the receptors located within them (in particular $\alpha$-adrenoreceptors). The latter aggravate the manifestation of LUTS [39]. Normalization of the tone of smooth muscle fibers can help to rehabilitate hormonal regulation of androgen-dependent tissues (by providing adequate androgen-replacement therapy [33]), and also, in the future, by restoring the pool of pluripotent stem cells which replenish the number of poorly differentiated progenitor epithelial cells and progenitor cells of other tissues [11,12]. 
The Influence of Partial Androgen Deficiency in Aging Men (PADAM) on the Development of Benign Prostatic Hyperplasia and Prostate Cancer

\section{Perspective Methods of Prevention and Treatment of Prostate Tumors}

The androgen blockade method has been widely used during treatment of prostate cancer for more than 60 years [40]. As a rule, establishment of the diagnosis of prostate cancer constitutes an androgen-dependent process, and as a result of the androgen blockade, tumor regression is observed among $70-80 \%$ patients. The significant reduction in the level of testosterone has a strong influence on the reduction of cancer of the prostate. Therefore, it is considered that the main task of conservative therapy of prostate cancer lies in restricting the influence of androgens on the prostate gland. This is achieved with the help of preparations that block the stimulation of the formation of testosterone by the testicles on the level of the hypothalamic-hypophysis, with the help of antiandrogens, orchiectomy, or various combinations of these methods [41]. However, a few years after the start of hormonal therapy, the majority of patients show a development of low-differentiated androgen-resistant prostate cancer [42]. The contradiction which arises when applying an androgen blockade is in the fact that men with prostate cancer are prescribed therapy which, in addition to the breach of production of testosterone due to age, reduces the action of androgens on the prostate tissues. Thus, the prescription of antiandrogens only intensifies the consequences of the age-related decrease of testosterone, and doesn't eliminate ethiological and all pathogenetic factors of the development of prostate cancer [8].

The androgen-dependent cells of the prostate require the presence of a physiologically necessary level of testosterone for further development. A decrease in the testosterone level is compensated by an increase in mitotic stimulation [8]. Natural immunity reactions are initiated by a series of chemical structures (glycoproteins, containing mannose, and others), that appear among old, proliferate and malignant cells [37]. Highly-active forms of oxygen and nitrogen, as well as other factors determine the cytolytic (including antineoplastic) action of monocytes, macrophages, neutrophils and cytotoxic T-cells to a significant degree [37, 38]. The use of antioxidants consistently decreases the effectiveness of the immune system response under an increase in mitotic activity of cells. Therefore the antiproliferative effect of a series of phytopreparations, described by many authors, is apparently caused not by their antioxidant activity, but rather by different reasons. When using a series of phytopreparations (Gentos), one can observe a decrease in the levels of luteinizing hormone, 5a-dihydrotestosterone and estradiol, the increase of which is observed during a decrease in testosterone production [43]. From this position, the use of a series of phytopreparations among patients with PADAM can be viewed as an analogue to androgen replacement therapy, and several of the components can be viewed as phytoandrogens (having a similar effect) [43]. At the same time, phytopreparations can't replace the missing testosterone completely. When there is an obvious need to conduct androgen-replacement therapy, the dose of the preparation shouldn't exceed the quantity of the hormone that decreases with age. The danger of prescribing surplus doses of testosterone preparations was shown in research done in the last century on mechanisms of development of prostate cancer. One can suppose that prescribing small doses of testosterone (suiting the age-related decrease in hormone production) [33] between courses of conducting an androgen blockade will help improve the results of treatment of patients with prostate cancer [8]. The androgen-replacement therapy will be effective for active surveillance of the abovementioned patients and for prevention in men 40 years of age and older of prostate cancer and benign prostatic hyperplasia, especially in men with the strong sexual constitution $[8,44]$.

Taking into account the many-staged oncogenesis [18] and the good, quick effect for atrophy of tumorous tissues, it's possible to expect the androgen blockade to be very promising under the condition that it will be done in relatively short cycles (no more than 6 months). Between cycles of androgen blockade and after them, as well as after high-dose rate (HDR) brachytherapy and radical prostatectomya, the recovery of division and differentiation of normal prostate cells by means of androgen-replacement therapy is necessary. It's not possible 
The Influence of Partial Androgen Deficiency in Aging Men (PADAM) on the Development of Benign Prostatic Hyperplasia and Prostate Cancer

to restore hormonal balance without the production of testosterone by the patient's own Leidig cells. For this reason, only a pharmacological androgen blockade can be considered effective (in view of its reversibility) [8, $13,44]$.

The daily dose of testosterone which enters the blood plasma when conducting androgen-replacement therapy among patients with PADAM should not exceed the loss of testosterone production that comes with age. Prescribing a large dose of the preparation leads to suppression of the body's own testosterone production while losing the circadian rhythm of incretion. When calculating the daily dose of testosterone, one should take into account the average daily production of testosterone in men [33]: $7 \mathrm{mg} /$ day [45]. One should also take the age-related decrease in testosterone production of $1 \%$ per year on average after 35 years of age for common testosterone into account. Androgen replacement therapy should be conducted continually $[11,12,33]$.

The perspective method for decreasing excess stimulation of mitotic activity and restoration of own production testosterone in people 40 years of age and older is the restoration of the number of a pool of pluripotent stem cells by transfusion of mononuclear fraction of peripheral blood from young donors of 18-23 years of age with the same blood types and sex as the recipient $[16,17,46]$.

\section{CONCLUSION}

When the production of testosterone is decreased in the male body, androgen-dependent cells turn out to be in the worst situation: an increase in the level of promoter factors of carcinogenesis in the blood plasma is accompanied by a breakdown in the development of cells during the androgen-dependent stage [10]. Likewise, cases of prostate cancer make up a significant part of all the oncological diseases among older-aged men. For this same reason, among men with prostate cancer, primary analysis usually reveals androgen-dependent tumors [21], which are formed from cells whose tumorous transformation began at the androgen-dependent stage. An increase in proliferate activity, together with insulin resistance, is a partial manifestation of metabolic syndrome, (X-syndrome), the development of which among men is due, to a significant extent, to an decrease in the production of testosterone and violation of tissue renewal $[8,11,12,17]$.

The recovery of testosterone production and regeneration helps make a decrease in proliferative activity and the rehabilitation of regulation of the androgen-dependence cells of the prostate and other tissues and organs, as well as to reduce insulin resistance among older men. These changes suggest that metabolic syndrome is possibly reversed (X-syndrome), which represents to a significant degree a phylogenetically-formed response to a decrease in testosterone production $[16,17,19]$.

\section{REFERENCES}

1. Kerkis YuYa. Physiological changes in the cell as a reason for the mutant process. Usp of Modern Biology. 1940; 1: 143-159.

2. Grin N, Stout W, Taylor D. Biology. Moscow: Mir Press; 1993.

3. Pechersky AV. Partial androgen deficiency among aging men. Influence on the growth of metabolic syndrome and pathology of the prostate gland. 3rd ed. St. Petersburg: SPb MAPO Press; 2007.

4. Teplyashin AS, Korzhikova SV, Sharifullina SZ, Chupikova NI, Rostovskaya MS, Savchenkova IP. Characteristics of human mesenchymal stem cells isolated from bone marrow and adipose tissue. Tsitologiya. 2005; 43 (2): $130-5$.

5. Gray A, Feldman HA, McKinlay JB, Longcope C. Age, disease, and changing sex-hormone levels in middleaged men: Results of the Massachusetts male aging study. Clin Endocinol. 1991; 73 (2): 1016-25.

6. Lopatkin NA. Guide to Urology. Moscow: Medicine; 1998. 
The Influence of Partial Androgen Deficiency in Aging Men (PADAM) on the Development of Benign Prostatic Hyperplasia and Prostate Cancer

7. Alberts B, Bray D, Lewis J, Raff M, Roberts K, Watson JD. Molecular biology of the cell. 2nd ed. Moscow: Mir; 1994.

8. Pechersky AV, Semiglazov VF, Loran OB, Mazurov VI, Karpischenko AI, Nikiforov AM, Kalinina NM, Drygina B, Davydova NI, Skorobogatykh MG. Changes in the level of cytokines among patients with prostate cancer after orchiectomy. Terra Medica, in its special thematic edition "Laboratory Diagnostics". 2003; 2: 26-30.

9. Pechersky AV, Semiglazov VF, Loran OB, Karpishenko AI, Pechersky VI, Mazurov VI. The influence of partial androgen deficiency (PADAM) on the impulse regime of incretion of several hormones and mitotic activity. Tsitologiya. 2006; 48 (10): 862 - 6.

10. Pechersky AV, Semiglazov VF, Komyakov BK, Guliev VG, Gorelov AI, Novikov AI, Pechersky VI, Simonov NN, Gulyaev AV, Samusenko IA, Vonsky MS, Mittenberg AG, Loran OB. Changes in the expression of receptors of steroid hormones in the presence of the development of partial age-related androgen deficiency (PADAM). Tsitologiya. 2005; 47 (4): 311-7.

11. Pechersky AV, Pechersky VI, Aseev MV, Droblenkov AV, Semiglazov VF. Several aspects of the regeneration process conducted by means multipotent stem cells. Tsitologiya. 2008; 50 (6): 511-20.

12. Pechersky AV, Pechersky VI, Aseev MV, Droblenkov AV, Semiglazov VF. Immune system and regeneration. Journal of Stem Cells. 2016; 11 (2): 69-87.

13. Pechersky AV, Mazurov VI, Semiglazov VF, Karpischenko AI, Mikhailichenko VV, Udintsev AV. Androgen administration in middle-aged and ageing men: Effects of oral testosterone undecanoate on dihydrotestosterone, estradiol and prostate volume. Intern J Andrology. 2002; 25: 119-25.

14. Lavin N. Endocrinology. 2nd ed. Moscow: Practica; 1999.

15. Vermeulen A, Kaufman JM. Androgens and cardiovascular disease in men and women. Aging Male. 1998; 1: 35-50.

16. Pechersky AV, Pechersky VI, Smolyaninov AB, Velyaninov VN, Adylov SF, Semiglazov VF. Application of cellular technologies for restoration of process of regeneration at people of the senior age groups. Herald of the North-Western State Medical University named after I.I. Mechnikov. 2014; 6 (4): 52-62.

17. Pechersky AV, Pechersky VI, Smolyaninov AB, Velyaninov VN, Adylov SF, Shmelev AYu, Pecherskaya OV, Semiglazov VF. Regeneration and carcinogenesis. Journal of Stem Cells. 2015; 10 (4): 255-70.

18. Bershtein LM. Hormonal cancergogenesis. Saint-Petersburg: Nauka; 2000.

19. Pechersky AV, Semiglazov VF, Mazurov VI, Karpishenko AI, Pechersky VI, Zybina NN, Davydova NI, Kravtzov VYu, Proshin SN, Skorobogatikh MG, Loran OB. The influence of partial age-related androgen deficiency on the development of metabolic syndrome. TERRA MEDICA nova, special edition "Laboratory diagnostics. 2006; 4: 12-9.

20. Pechersky AV. Role of partial androgen deficiency of aging men in development of the metabolic syndrome. American Research Journal of Urology. 2016; 1: 1-13.

21. Moiseenko VM, Urmacheyeva AF, Hanson KP. Lectures on fundamental and clinical oncology. SaintPetersburg: N-L Publishers; 2004.

22. Pechersky AV, Mazurov VI, Semiglazov VF, Karpischenko AI, Udintsev AV. The influence of the level of testosterone on the formation of $5 \alpha$-dihydrotestosterone and $17 \beta$-estradiol in the testosterone-sensitive cell line of fibroblasts of the foreskin. Tsitologiya. 2005; 47 (2): 172-4. 
The Influence of Partial Androgen Deficiency in Aging Men (PADAM) on the Development of Benign Prostatic Hyperplasia and Prostate Cancer

23. Kjellman A., Akre 0, Norming U, Tornblom M, Gustafsson O. Dihydrotestosterone levels and survival in screening-detected prostate cancer: A 15-yr follow-up study. European Urology. 2008; 53 (1): 106-11.

24. Zazerov VG, Severin ES. Molecular mechanisms of oncogenesis of the prostate. Herald of the Russian Academy of Medical Sciences. 1998; 5: 29-35.

25. Tsai MJ, Clark J, Schrader WT, O'Malley BW. Mechanisms of action of hormones that act as transcriptionregulatory factors. Wilson JD, editor. Williams text-book of endocrinology. Philadelphia: WB Saunders; 1998.

26. Prehn RT. On the prevention of prostate cancer by androgen administration. Cancer Res. 1999; 59 (17): 4161-4.

27. Andreeva UU, Danilova VV, Moskvina LV, Zavalishina LE, Kekeeva TV, Malkov PG, Frank GA. Tumors of an urinary system and male genitals. Morphological diagnostics and genetics. Moscow: Practicheskaya medicina; 2012.

28. Thompson IM, Goodman PJ, Tangen CM, Scott Lucia M, Miller GJ, Ford LG, Lieber MM, Cespedes RD, Atkins JN, Lippman SM, Carlin SM, Ryan A, Szczepanek CM, Crowley JJ, Coltman CA. The influence of finasteride on the development of prostate cancer. N Engl J Med. 2003; 349: 215-24.

29. Pechersky AV, Loran OB, Pechersky VI, Vonsky MS, Mittenberg AG, Semiglazov VF. The role of testosterone in regulation of the expression of genes of several proliferation factors. Tsitologiya. 2006; 48 (10): 856-61.

30. Costello LC, Franklin RB. Effect of prolactin on the prostate. Prostate. 1994; 24: 162-8.

31. Bershtein LM. Extragonadal production of estrogens (their role in physiology and pathology). SaintPetersburg: Nauka; 1998.

32. Tareeva IE. Nephrology. Moscow: Medicina; 1995.

33. Pechersky AV. Features of diagnostics and treatment of partial androgen deficiency of aging men. Central European Journal of Urology. 2014; 67 (4): 397-404.

34. Kettail VM, Arki PA. Pathophysiology of the endocrinal system. Saint-Petersburg: Nevsky Dialect; 2001.

35. Karpishenko AI. Medicinal Laboratory Diagnostics. Saint-Petersburg: Intermedika; 2001.

36. Berezov TT, Korovkin BF. Biological Chemistry. Moscow: Medicina; 2004.

37. Yarilin AA. Foundations of Immunology. Moscow: Medicina; 1999.

38. Roitt I, Brostoff J, Male D. Immunology. Moscow: Mir; 2000.

39. Pechersky AV, Dombrovskaya YA, Pecherskaya OV, Moroz BT. The role of sex hormones in regulating the expression of insulin receptors and microcirculation. Herald of St-Petersburg Medical Academy of Postgraduate Studies. 2010; 2 (1): 28-33.

40. Petrylak DP. Chemoterapy for the Treatment of hormone-refractory prostate cancer. European Urology Supplements. 2002; 2: 15-23.

41. Stepanov VN, Shimanovsky NL. Androcure-preparation of the first line inpalliative treatment of inoperable prostate cancer. Moscow Medical Journal. 2000; 8: 26-31.

42. Pummer $\mathrm{K}$. The role of urologist in the management of hormone-refractory prostate cancer. European Urology Supplements. 2002; 2: 24-8. 
The Influence of Partial Androgen Deficiency in Aging Men (PADAM) on the Development of Benign Prostatic Hyperplasia and Prostate Cancer

43. Pechersky AV, Alexandrov VP, Mazurov VN, Knyazkin IV, Zezyulin PN, Nikolayeva EV. Treatment of benign prostate hyperplasia using Gentos. Urology (RU). 2000; 5: 16-7.

44. Pechersky AV. About mechanisms of development of a prostate cancer and a substantiation of perspective methods of treatment of the given disease. Proceedings of the VII International Scientifically-Practical Conference: Advanced Achievements of the european science; 2011 Jun 17-25; Sofia: Byl GRAD-BG, 2011.

45. Morales A, Schulman C, Tostain J, Wu F. Selecting the correct terminology for testosterone deficiency. J Clin Endocrinol Metab. 2006; 50: 407-9.

46. Pechersky AV. Influence of violation of regeneration in people over 35-40 years old on decrease in production of sexual hormones. Journal of Stem Cells. 2016; 11 (2): 99-109.

Citation: Alexander V. Pechersky. "The Influence of Partial Androgen Deficiency in Aging Men (PADAM) on the Development of Benign Prostatic Hyperplasia and Prostate Cancer". American Research Journal of Urology, 2019; 3(1): 1-16.

Copyright (c) 2019 Alexander V. Pechersky. This is an open access article distributed under the Creative Commons Attribution License, which permits unrestricted use, distribution, and reproduction in any medium, provided the original work is properly cited. 